This item was submitted to Loughborough's Research Repository by the author.

Items in Figshare are protected by copyright, with all rights reserved, unless otherwise indicated.

\title{
Physiological effects of the addition of $n$-dodecane as an oxygen vector during steady-state Bacillus licheniformis thermophillic fermentations perturbed by a starvation period or a glucose pulse
}

\section{PLEASE CITE THE PUBLISHED VERSION}

\section{PUBLISHER}

(C) Elsevier

\section{VERSION}

AM (Accepted Manuscript)

LICENCE

CC BY-NC-ND 4.0

\section{REPOSITORY RECORD}

da Silva, Teresa Lopes, Alberto Reis, J. Carlos Roseiro, and Christopher J. Hewitt. 2009. "Physiological Effects of the Addition of N-dodecane as an Oxygen Vector During Steady-state Bacillus Licheniformis Thermophillic Fermentations Perturbed by a Starvation Period or a Glucose Pulse". figshare. https://hdl.handle.net/2134/4082. 
This item was submitted to Loughborough's Institutional Repository (https://dspace.lboro.ac.uk/) by the author and is made available under the following Creative Commons Licence conditions.

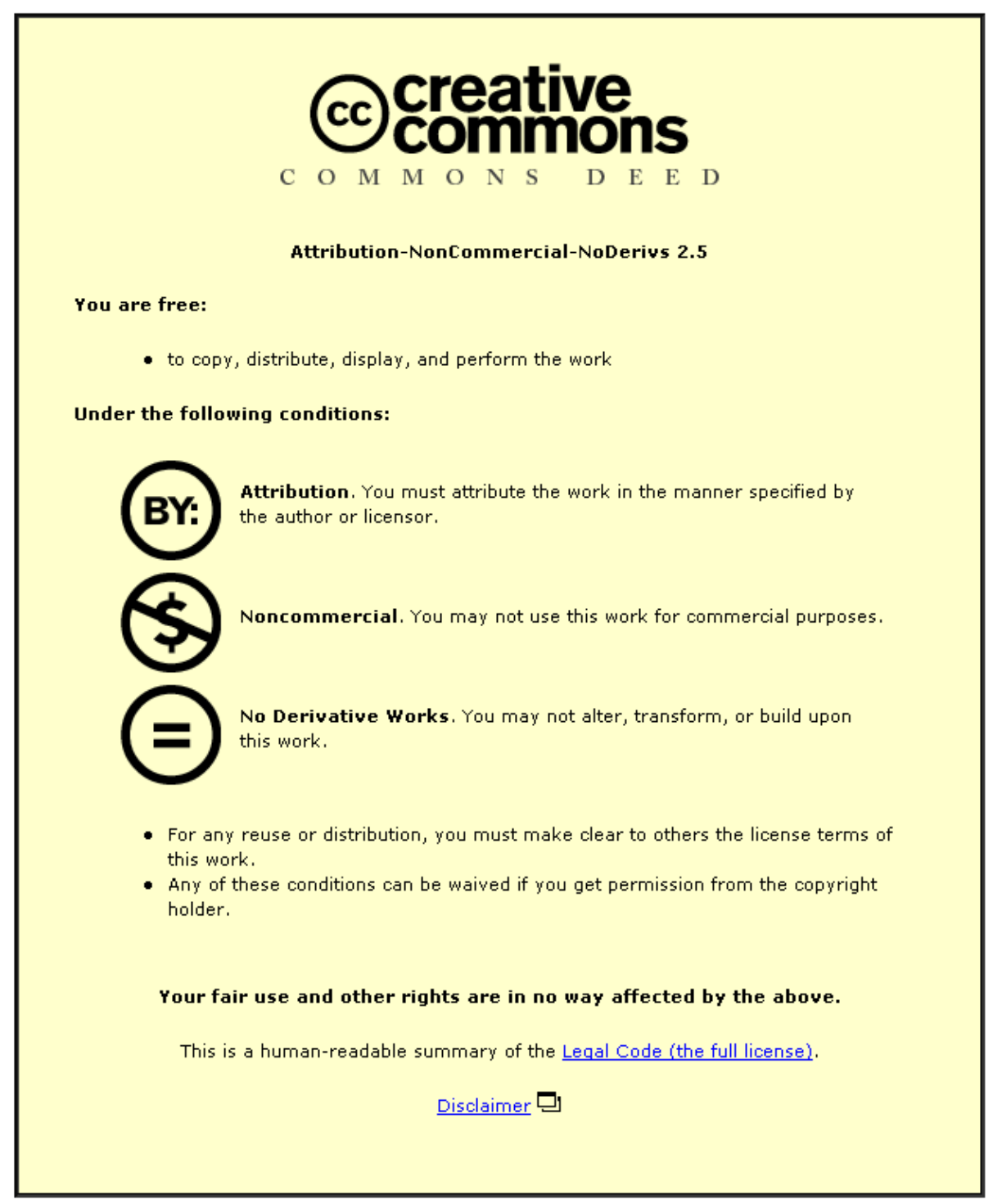

For the full text of this licence, please go to: http://creativecommons.org/licenses/by-nc-nd/2.5/ 


\section{Publications Category 11}

\section{Journal Papers - Academic Journals}

Title of Work: $\left(^{*}\right)$

Physiological effects of the addition of n-dodecane as an oxygen vector during steadystate Bacillus licheniformis thermophillic fermentations perturbed by a starvation period or a glucose pulse

Major Work: (*)

Biochemical Engineering Journal.

Volume:

42

Issue:

N/A

Year of Publication: $\left(^{*}\right)$

2008

Page Numbers: $(*)$

208-216

ISBN No:

1369-703X

D.O.I. (Digital Object Identifier): (*)

10.1016/j.bej.2008.06.023

Authors: (*)

Lopes da Silva T., Reis A., and Hewitt C. J.
Total Number of Pages: $(*)$

9

ISSN No:

(* denotes field must be completed) 


\section{Physiological effects of the addition of n-dodecane as an oxygen vector during steady-state Bacillus licheniformis thermophillic fermentations perturbed by a starvation period or a glucose pulse}

Teresa Lopes da Silva ${ }^{(1)^{*}}$, Alberto Reis ${ }^{(1)}$, J. Carlos Roseiro ${ }^{(2)}$ and Christopher J. Hewitt (3)

(1) Instituto Nacional de Engenharia, Tecnologia e Inovação, Departamento de Biotecnologia, Unidade de Bioengenharia e Bioprocessos, Estrada do Paço do Lumiar, 22, 1649-038 Lisboa Codex, Portugal.

(2) Instituto Nacional de Engenharia, Tecnologia e Inovação, Departamento de Biotecnologia, Laboratório de Microbiologia Industrial, Estrada do Paço do Lumiar, 22, 1649-038 Lisboa Codex, Portugal.

(3) Interdisciplinary Centre for Biological Engineering, Department of Chemical Engineering, Loughborough University, Leicestershire, LE11 3TU, UK

*corresponding author: teresa.lopesilva@ineti.pt

Keywords: Bacillis licheniformis, n-dodecane, multi-parameter flow cytometry, oxygen vector, steady-state Thermophilic, wastewater treatment 


\begin{abstract}
The effect of the presence of $n$-dodecane as a potential oxygen vector during oxygenlimited continuous cultures of a Bacillus strain was studied, under extreme nutrient supply conditions: glucose excess, limitation and starvation. The addition of n-dodecane to the aqueous phase of a mechanically agitated and aerated fermentation increased the $k_{L} a$ by up to $35 \%$. The $\mathrm{n}$-dodecane additions to $B$. licheniformis cells during starvation (oxygen limitation with concomitant glucose starvation) caused a severe detrimental progressive change in cell physiological state with respect to cytoplasmic membrane polarisation and permeability which was mitigated against by alleviating either the oxygen limitation (by increasing the mean energy dissipation rate or by the addition of n-dodecane as an oxygen vector) or by alleviating the carbon limitation (by resuming the carbon feed or by the addition of a glucose pulse). Further that during periods of excess glucose (glucose pulse) a much higher $k_{L} a$ was required to prevent the onset of anaerobic mixed acid fermentation than could be provided by the addition of $\mathrm{n}$-dodecane alone. $\mathrm{N}$-dodecane can be used to increase the $k_{L} a$ when added in sufficient quantities to the aqueous phase of a mechanically agitated and aerated bioreactor but the magnitude of this increase is process and vessel geometry specific.
\end{abstract}




\section{Introduction}

Thermophilic aerobic wastewater treatment has many of the same benefits as thermophilic composting and sludge digestion, such as faster waste degradation rates, rapid inactivation of pathogenic micro-organisms, and low sludge yields. However, the oxygen requirements of such systems are high and can be considered to be a disadvantage when compared to anaerobic technologies [1]. Indeed, the most important consideration regarding the use of thermophilic reactors is the requirement to match the high oxygen uptake rate imposed by rapid COD consumption at high temperatures given that the saturation concentration of dissolved oxygen in the water-like growth medium is relatively low. Oxygen requirements in these systems have been estimated to be $\sim 14 \%$ higher than for conventional aerobic processes [2] such that Rozich and Colven [3] recommended using extremely high power inputs, gas blending and a greater tank depth to satisfy the large oxygen requirement of thermophilic treatment processes. However, these can be costly options and difficult to achieve in practice especially where available space is at a premium so the selection of alternative regimes that maximise oxygen transfer becomes one of the most critical process design choices. It is known that oxygen transfer in microbial fermentations can be enhanced by adding an organic phase with a higher affinity for oxygen i.e. an oxygen vector [4]. Oxygen vectors are defined as compounds that, when added to the growth medium, can enhance the oxygen transfer rate to the cell, resulting from the higher oxygen solubility in the organic phase when compared with a water-like growth medium [5]. In this case, oxygen transfer can occur directly to cells, or via oxygen-vectors either adsorbed or not to the air bubble surface. [6,7]. Whereas no more than the saturation concentration of oxygen can be dissolved in the aqueous phase, the supply of oxygen to the aqueous phase from the gas stream may be supplemented by equilibrium partitioning of dissolved oxygen 
from the organic phase to the aqueous phase. Indeed a number of wokers have used oxygen vectors to successfully enhance oxygen transfer and, as a consequence, have increased the biomass concentration and hence process performance in a number of different culture systems [8,9]. Examples of common hydrocarbon oxygen vectors include n-dodecane, nhexadecane $[10,11,12,13,14,15,16]$ perfluorocarbons $[9,17,18]$ and a number of vegetable oils [19]. The isolation of cultures from thermophilic aerobic wastewater treatment reactors has revealed that thermophilic Bacillus spp. are the dominant organisms present $[1,2,20]$. During such highly aerobic processes oxygen requirements are often over estimated because DOT measurements are impossible to make because the DOT probe rapidly becomes coated with a biofilm. This often leads to excessive power inputs of $>30 \mathrm{kWm}^{-3}$ and aeration rates of $\sim 4$ vvm being used to 'ensure' oxygen-sufficient conditions [21]. Therefore in this work the effect of the presence of n-dodecane as a potential oxygen vector during oxygen-limited continuous cultures of a Bacillus strain (previously isolated from an aerobic bioremediation reactor) was studied, under extreme nutrient supply conditions: glucose excess, limitation and starvation. Such conditions are often present in large-scale fermentations ( $>5000 \mathrm{~L}$ dependent on vessel geometry) due to poor mixing [22] where cells experience rapidly changing microenvironments with respect to substrate concentrations when circulating around a bioreactor. In order to evaluate the physiological response of Bacillus licheniformis to the range of conditions described individual cell physiological response was measured by multi-parameter flow cytometry as well as more conventional microbiological analytical techniques and a comparison made. 


\section{Materials and Methods}

\section{Organism}

B. licheniformis was previously isolated from an aerobic wastewater treatment reactor (Sustainable Biowaste Solutions Ltd, Peterborough, UK) and deposited in the Industrial Micro-organisms Culture Collection (National Institute of Engineering, Technology and Innovation, Lisbon, Portugal), with the reference code CCMI 1034. Lyophilized cell cultures of Bacillus cereus NCTC1143 were also used to provide control data.

\section{Bioreactor experiments}

Cells from six nutrient agar plates grown for $24 \mathrm{~h}$ at $45{ }^{\circ} \mathrm{C}$ were transferred to the growth medium (GM) which was made up as follows: glucose $5 \mathrm{~g} \mathrm{l}^{-1} ; \mathrm{KH}_{2} \mathrm{PO}_{4} 1 \mathrm{~g} \mathrm{l}^{-1} ;\left(\mathrm{NH}_{4}\right)_{2} \mathrm{SO}_{4}$ $1.5 \mathrm{~g} \mathrm{l}^{-1}$; yeast extract $0.25 \mathrm{~g} \mathrm{l}^{-1} ; \mathrm{CaCl}_{2} \cdot 2 \mathrm{H}_{2} \mathrm{O} 0.1 \mathrm{~g} \mathrm{l}^{-1} ; \mathrm{MgCl}_{2} \cdot 7 \mathrm{H}_{2} \mathrm{O} 0.25 \mathrm{~g} \mathrm{l}^{-1}$ and supplemented with $2 \mathrm{ml}$ Vishniac trace elements solution [23] to inoculate the bioreactor. After a period of batch culture, a pump was used to feed sterile GM into the fermenter at a dilution rate of $0.20 \mathrm{~h}^{-1}$. Steady-state parameters were determined by periodic analysis of biomass concentration $\left(\mathrm{g}^{-1}\right)$ and residual glucose concentration $\left(\mathrm{g} \mathrm{l}^{-1}\right)$. All experiments were carried out in an Infors HT benchtop fermenter (Infors, Reigate, Surrey, UK), with a 1.21 working volume, equipped with two six-bladed Rushton impellers $(\mathrm{d}=0.048 \mathrm{~m})$. The two impellers were positioned $0.042 \mathrm{~m}$ apart with the lower impeller situated $0.032 \mathrm{~m}$ above the bottom of the vessel. The vessel was fitted with three equally spaced baffles, width $0.015 \mathrm{~m}$. The working volume was kept constant by using a surface dipped levelling tube linked to a variable speed peristaltic pump. Culture agitation was set at $500 \mathrm{rpm}$ unless otherwise stated, and the aeration rate at $1 \mathrm{vvm}$. Continuous, DOT measurements were impossible because the polarographic dissolved oxygen probe used in this work became 
rapidly coated with a biofilm early on during fermentations. However, the biofilm was aseptically removed from the oxygen probe in all steady-states prior to the batch periods (starvation and glucose pulse), so that steady-state DOT readings could be taken. The temperature was controlled at $45^{\circ} \mathrm{C}$ and $\mathrm{pH}$ was controlled automatically by the addition of $2 \mathrm{M} \mathrm{NaOH}$ or $2 \mathrm{M} \mathrm{HCl}$ on demand to $6.8+0.1$.

\section{Oxygen vector}

n-dodecane (Merck, Darmstadt, Germany; oxygen solubility $54.9 \times 10^{-3} \mathrm{~g}^{-1}$ at $35^{\circ} \mathrm{C}$ and atmospheric air pressure) was added to the sterile fermentation broth at different volumetric fractions $1,2.5$ and $5 \%(\mathrm{v} / \mathrm{v})$ as appropriate.

\section{$k_{L} a$ measurements}

$\mathrm{k}_{\mathrm{L}} \mathrm{a}$ measurements were made using a polarographic dissolved oxygen electrode (Ingold, USA) in sterile growth medium because of the problems associated with DOT probe membrane fouling. The gas-liquid mass transfer coefficient $\left(k_{L} a\right)$ was calculated by measuring the rate of oxygen transfer in nitrogen purged fermentation broth, at $45^{\circ} \mathrm{C}$ following the method described in [24].

\section{Glucose pulse}

Once the steady-state was reached $\left(\mathrm{D}=0.20 \mathrm{~h}^{-1}\right)$, the medium feed pump was switched-off, and a glucose pulse $\left(6 \mathrm{~g} \mathrm{l}^{-1}\right.$ final concentration) containing the other GM nutrients (at the same proportion to the feed) were added to allow a period of batch growth and carbon source exhaustion to occur. $\mathrm{N}$-dodecane was added at either $1,2.5$ and $5 \% \mathrm{v} / \mathrm{v}$ final concentration, simultaneously with the glucose and the GM nutrients. In some cases the 
impeller speed was also increased from $500 \mathrm{rpm}$ to $1000 \mathrm{rpm}$ at the same time as the glucose pulse was added. Samples were withdrawn from the bioreactor at regular time intervals for determination of biomass, glucose and organic acids concentration as well as for analysis by multi-parameter flow cytometry.

\section{Starvation period}

Starvation periods were carried out under the same conditions as the glucose pulse but without any nutrients added at all. N-dodecane was added in the same concentrations as previously described. The dilution rate before the starvation period $\left(0.20 \mathrm{~h}^{-1}\right)$ was kept the same for each experiment in order to try and ensure comparable physiological starting conditions in all cases (glucose pulse and starvation period). Once the steady-state was reached, the nutrient feed-line and outlet culture pumps were switched-off to allow a period of nutrient starvation to occur. Samples were withdrawn from the bioreactor at regular time intervals for determination of biomass, glucose and organic acids concentration as well as for analysis by multi-parameter flow cytometry.

\section{Flow cytometry}

The analytical methods used were essentially the same as in previous articles $[21,25]$, so only an outline will be given here. Multi-parameter flow cytometry was used to establish the physiological state of the cells, using a Coulter Epics Elite analyser (BeckmanCoulter, UK). The advantages of multiparameter flow cytometry over the more conventional microbiological techniques such as dilution plating (c.f.u. per ml) are well documented $[26,27]$ but, briefly, using various mixtures of fluorescent dyes it is possible to resolve an individual microbial cells physiological state beyond culturability based on the presence or 
absence of an intact polarised cytoplasmic membrane and the transport mechanisms across it, enabling assessment of population heterogeneity. In all cases the properties of at least 50,000 cells were measured. In addition, cell biomass $\left(\mathrm{OD}_{600 \mathrm{~nm}}\right.$, dry cell weight, $\left.\mathrm{g} \mathrm{l}^{-1}\right)$, glucose and organic acids concentrations $\left(\mathrm{g} \mathrm{l}^{-1}\right)$ were measured throughout the fermentations.

\section{Results and Discussion}

Flow cytometry controls

A number of flow cytometry control data sets were established in order to show that Bacillus licheniformis could be reliably stained with PI and $\mathrm{DiOC}_{6}(3)$ and to provide base line data for comparison with that taken from the steady state of the continuous culture and subsequent experimental perturbations. The cytoplasmic membrane potential in prokaryotes is known to be between $100-200 \mathrm{mV}$, the exact magnitude depending on the metabolic activity of the cell with the inside of the cell negative with respect to its exterior [28]. In general Gram +ve cells have a lower maximum cytoplasmic membrane potential than Gram -ve cells. Therefore cationic stains that accumulate proactively (i.e. it enters and stains the cell when the cytoplasmic membrane is polarised) are often thought to be preferential for reflecting changes in membrane potential in Gram +ve organisms [39] to those anionic stains commonly used with Gram -ve cells. Indeed only $\sim 40 \%$ of a Rhodococus sp. cell population was able to generate a sufficiently high cytoplasmic membrane potential to exclude bis-(1, 3-dibutylbarbituric acid) trimethine oxonol (anionic) during nutrient sufficient conditions [30]. In this work it is shown that even when Bacillus licheniformis cells are taken from the steady state of a continuous culture and stained with a mixture of PI and BOX only two populations of cells could be readily identified (Figure 
1i). Sub-population located in the lower left quadrant, with no staining was largely absent. Indeed in this study (not all data shown) B. licheniformis was unable to generate a sufficiently high cytoplamsic membrane potential to exclude BOX at any time during its growth cycle (including uncontrolled rapid growth) and in this and other such cases BOX cannot be used reliably to monitor changes in individual cell cytoplasmic membrane potential. Therefore in this work we have shown that the Gram +ve bacteria Bacillus cereus NCTC1143 and Bacillus licheniformis can be rapidly stained with a mixture of PI and $\mathrm{DiOC}_{6}(3) . \mathrm{DiOC}_{6}(3)$ is cationic and accumulates intracellularly when the cytoplasmic membrane is polarised or hyperpolarized. Normally, as is the case with, B. cereus (Figure 1 ii), up to three sub-populations are readily identifiable. These correspond to cells with an intact polarised cytoplasmic membrane, stained with $\mathrm{DiOC}_{6}(3)(\mathrm{A})$, cells with an intact depolarised cytoplasmic membrane, not stained (B) and cells with a permeablised depolarised cytoplasmic membrane stained with PI only (C). However, in the case of stationary phase Bacillus licheniformis cells a fourth sub-population can be identified (D) (Figure 1 iii). This corresponds to cells stained with both PI and $\mathrm{DiOC}_{6}(3)$, paradoxically this would mean that cells had a permeablised but polarised cytoplasmic membrane. To investigate this phenomenon further B. lichenformis cells were taken from the steady state of the continuous culture and either incubated in the presence of $15 \mu \mathrm{g} \mathrm{ml}^{-1}$ (for $10 \mathrm{~min}$ ) of carbonyl cyanide $m$-chlorophenylhydrazone (CCCP, a known ionophore used to collapse cytoplasmic membrane potential [29]), heat treated at $60^{\circ} \mathrm{C}$ for $30 \mathrm{~s}$ or washed in $100 \%$ ethanol. Such cells were then stained with a mixture of PI and $\mathrm{DiOC}_{6}(3)$ and compared with untreated cells. Only cells treated with the CCCP excluded $\mathrm{DiOC}_{6}(3)$ (Figure 2) and PI whilst only the untreated cells excluded the PI. These data support (experimentally) the theories put forward by earlier studies $[28,31]$, that with lipohilic cationic carbocyanine 
dyes such as $\mathrm{DiOC}_{6}(3)$ non-specific energy independent binding can occur when the hydrophobic regions of disrupted cytoplasmic membranes, become exposed to such harsh conditions as exposure to lethal heat, dehydration in ethanol and sometimes severe nutrient limitation.

\section{$k_{L}$ a measurements}

Figure 3 shows the variation of $k_{L} a$ with the impeller speed (500 rpm and $1000 \mathrm{rpm}$ ) and with 1, 2.5 and 5\% n-dodecane added to the sterile culture broth with a volumetric gas flow rate of $1 \mathrm{vvm}$. The highest $k_{L} a$ was obtained at $1000 \mathrm{rpm}\left(71.3 \mathrm{~h}^{-1}\right)$ as compared with the $k_{L} a$ obtained at $500 \mathrm{rpm}\left(31.0,36.4,38.0\right.$ and $28.1 \mathrm{~h}^{-1}$ obtained at $1,2.5$ and $5 \% \mathrm{v} / \mathrm{v} \mathrm{n}$ dodecane and no n-dodecane added, respectively). Therefore the $k_{L} a$ was increased in $\sim 10$, 30 and $35 \%$ when the n-dodecane was added to the sterile culture broth stirred at $500 \mathrm{rpm}$, at $1,2.5$ and $5 \%(\mathrm{v} / \mathrm{v})$, respectively. This is in contrast to a $\sim 150 \%$ increase in $k_{L} a$ when the impeller speed was raised from $500 \mathrm{rpm}$ to $1000 \mathrm{rpm}$ in essentially the same system. However, the later represents a $\sim 10$ fold increase in mean specific energy dissipation rate $\left(\bar{\varepsilon}_{T}\right)$ from $0.7-7 \mathrm{~W} \mathrm{Kg}^{-1}$. These findings are in agreement with other work where ndodecane was used as an oxygen vector in microbial fermentations $[12,13,32]$, although the exact $k_{L} a$ values are strongly dependent on other factors such as bioreactor geometry and growth medium composition.

\section{Starvation period}

Figures 4 and 5 show representative biomass, organic acid and physiological profiles of a B. licheniformis steady-state culture subjected to a starvation period (nutrient feed shut off) of $6 \mathrm{~h}$ duration at two agitation intensities $(500 \mathrm{rpm}$ and $1000 \mathrm{rpm})$ and in the presence or 
not of one of three concentrations of n-dodecane $(1,2.5$ and $5 \% \mathrm{v} / \mathrm{v})$. In all cases just before the starvation period the biomass concentration was in the range $\sim 1.5-2 \mathrm{~g} \mathrm{l}^{-1}$, glucose was $0 \mathrm{~g} \mathrm{l}^{-1} 1$, both acetic acid and formic acid had accumulated to between $\sim 1-1.2 \mathrm{~g}$ $1^{-1}$ and $\sim 0.05-0.12 \mathrm{~g} \mathrm{l}^{-1}$ respectively and DOT was less than $5 \%$, This indicated that oxygen was limiting during the preceding period of steady-state growth (held at $500 \mathrm{rpm}$ ) and both formic as well as acetic acid are known to accumulate via the redirection of pyruvate during mixed acid fermentation when oxygen is limiting $[33,34,35,36,37,38,39,40]$. Interestingly, though this did not result in a large proportion of cells with depolarised or permebalised (dead) cytoplasmic membranes probably because this B. licheniformis strain is known to be a facultative anaerobe [37]. Further, during a similar steady-state (data not shown) but held at $1000 \mathrm{rpm}$ no organic acids were detected, and the biomass yield was higher $\sim 0.5 \mathrm{~g}$ biomass (g glucose) ${ }^{-1}$ when compared to that of $\sim$ $0.3 \mathrm{~g}$ biomass $(\mathrm{g} \text { glucose })^{-1}$ observed at $500 \mathrm{rpm}$. This indicates and supports the work of others who showed that under oxygen sufficient conditions, B. licheniformis can convert glucose to biomass more efficiently but it is still able to consume glucose under oxygen limiting conditions $[39,41]$. In all cases formic acid had been completely consumed $2 \mathrm{~h}$ into the starvation period with acetic acid completely consumed by $5 \mathrm{~h}$ both with similar volumetric uptake rates (Table 1) but, during this period there was little increase or decrease in biomass concentration presumably the ATP derived was being used for cell maintenance rather than growth. In the case of the starvation period held at $500 \mathrm{rpm}$ without any n-dodecane added and with $1 \% \mathrm{v} / \mathrm{v}$ n-Dodcecane added there was a substantial and progressive detrimental change in cell physiological state throughout the six hour period with a decrease in the proportion of cells stained with only $\operatorname{DiOC}_{6}(3)$ which was 
more pronounced in the former rather than the latter case. This meant that the 'healthy biomass' (i.e. stained with $\mathrm{DiOC}_{6}(3)$ only) was consuming more of the organic acids on a $\mathrm{g} \mathrm{g}_{-}{ }^{1}$ 'healthy biomass' basis. In all other cases there was little change in cell physiological state throughout. This is attributed to conditions of both oxygen limitation and glucose exhaustion in the case of the starvation periods held at $500 \mathrm{rpm}$ with no $\mathrm{n}$-dodecane added and with $1 \% \mathrm{v} / \mathrm{v}$ n-dodcecane added. Presumably, the oxygen limitation could have been less in the latter case because of the presence of the oxygen vector. In all other cases whilst conditions of glucose exhaustion existed there was reduced oxygen limitation because of a higher $K_{L} a$ due to either a higher agitation intensity or the presence of n-dodecane in a sufficiently high enough concentration to prevent oxygen limitation and hence a detrimental change in cell physiological state. However, the beneficial effect of n-dodecane may not be entirely attributable to the alleviation of oxygen limitation because n-dodecane can be metabolised if it is the sole carbon source present $[10,42]$ and a reliable method for measuring n-dodecane concentration was not available during this study so this warrants further investigation. Examination of samples collected during the starvation period using traditional optical light microscopy did not show any increase in the proportion of endospores when compared to the steady-state in all the cases. N-dodecane toxicity at the concentrations used can be discounted because there was little detrimental change in physiological state when even 5\% was added to the steady-state culture (Figure 5).

\section{Glucose pulses}

Figures 6 and 7 show representative biomass, organic acid and physiological profiles for $6 \mathrm{~h}$ after a $B$. licheniformis steady-state culture was subjected to a $\sim 5 \mathrm{~g}^{-1}$ glucose pulse at two agitation intensities (500 rpm and $1000 \mathrm{rpm}$ ) and in the presence or not of one of three 
concentrations of $\mathrm{n}$-dodecane $(1,2.5$ and $5 \% \mathrm{v} / \mathrm{v})$. In all cases, just before the glucose pulse addition, DOT was less than $5 \%$, indicating that oxygen was limiting during the previous steady-states. Both formic acid and acetic acid accumulated during the steady state as before presumably for similar reasons. Although the biomass, organic acid concentrations and physiological profiles just before the glucose addition point were not exactly the same, such differences have been reported before [29,43] and are explained by long term physiological oscillations, multiple steady-states and genetic instabilities which are known to occur during continuous culture of some Bacillus spp. In all cases the glucose was consumed by $2 \mathrm{~h}$ after the addition. For all fermentations pyruvic, lactic and propionic acids accumulated for $2 \mathrm{~h}$ after the glucose addition and were then consumed when the glucose was exhausted. The maximum concentration of each was measured at $2 \mathrm{~h}$ post glucose addition and was similar in all cases where n-dodecane was added but lower in the absence of the oxygen vector. Formic acid started to be consumed immediately on addition of the glucose in all fermentations. In the case of the fermentation carried out at $1000 \mathrm{rpm}$, acetic acid was the dominant organic acid that accumulated and was consumed immediately after glucose exhaustion (Figure 6a), this change in substrate utilisation is well documented [36] and allows cells to survive in the absence of a more readily assimilable carbon source [39]. Here the acetic acid is used for cell maintenance rather than growth since there was no measurable increase in biomass concentration throughout this period $\left(Y_{\text {biomsass/acetic acid }}=0 \mathrm{~g}\right.$ biomass (g acetic acid) ${ }^{-1}$ Table 1). The switch to the use of acetic acid was accompanied by a transient detrimental change in cell physiological state as measured by fluorescent staining. In all the other fermentations there was very little change in cell physiological state throughout and the patterns of acetic acid accumulation and utilisation were very different. In all of these fermentations acetic acid was either utilised or remained constant 
during glucose consumption then increased rapidly on glucose exhaustion during which period the other organic acids present were consumed with little or no accompanying increase in biomass concentration, although the acetic acid yields with respect to glucose ( $\mathrm{Y}_{\text {acetic acid/glucose }}$ ) were different (Table 2). As expected, the highest biomass yield with respect to the amount of glucose consumed ( $Y_{\text {biomass/glucose }}$ ) was measured in the fermentation at $1000 \mathrm{rpm}\left(0.23 \mathrm{~g} \mathrm{~g}^{-1}\right)$, indicating that the higher oxygen availability in the broth due to the higher $K_{L} a$ allowed carbon assimilation via the tricarboxylic acid cycle, resulting in biomass production. The lowest $\mathrm{Y}_{\text {biomass/glucose }}\left(0 \mathrm{~g}\right.$ biomass $\left.(\mathrm{g} \text { glucose })^{-1}\right)$ was observed in the fermentation at $500 \mathrm{rpm}$ with no n-dodecane added (Table 2), indicating that oxygen limitation occurred with carbon redirected towards the products of anaerobic mixed acid fermentation resulting in little cell growth. The remaining fermentations, i.e., $500 \mathrm{rpm}$ with 1, 2.5 and $5 \%(\mathrm{v} / \mathrm{v})$ n-dodecane displayed a slightly higher biomass yield $\left(0.05,0.06\right.$ and $0.08 \mathrm{~g}$ biomass $(\mathrm{g} \text { glucose })^{-1}$ respectively), indicating that the increased $K_{L} a$ due to the oxygen vector increased oxygen availability in these fermentations, thus allowing a partial carbon conversion to biomass. Similarly, the other organic acids yields with respect to glucose $\left(\mathrm{Y}_{\text {Pyruvic/Glucose, }} \mathrm{Y}_{\text {Propionic/Glucose, }} \mathrm{Y}_{\text {Lactic/Glucose, Table 2) followed the }}\right.$ same trend. In all cases microscopical observation indicated no endospore formation in response to the environmental conditions imposed.

\section{Conclusions}

Dual staining with PI and $\operatorname{DiOC}_{6}(3)$ and simultaneous measurement of emitted fluorescence can be used to monitor the physiological state of some Bacillus spp. but the 
interpretation of such data can only be reliably done when the necessary control experiments have been carried out.

$\mathrm{N}$-dodecane can be used to increase the $k_{L} a$ when added in sufficient quantities to the aqueous phase of a mechanically agitated and aerated bioreactor but the magnitude of this increase is process and vessel geometry specific. The toxic effects of n-dodecane on the Bacillus spp tested at concentrations of up to $5 \%(\mathrm{v} / \mathrm{v})$ can be largely discounted.

The imposition of oxygen limitation coupled with glucose starvation causes a severe detrimental progressive change in cell physiological state with respect to cytoplasmic membrane polarisation and permeability. However, this can be mitigated against by alleviating either the oxygen limitation (by increasing the mean energy dissipation rate or by the addition of $n$-dodecane as an oxygen vector) or by alleviating the carbon limitation (by resuming the carbon feed or by the addition of a glucose pulse). Further that during periods of excess glucose (glucose pulse) a much higher $K_{L} a$ was required to prevent the onset of anaerobic mixed acid fermentation than could be provided by the addition of ndodecane alone. The latter has implications for the scale-up of such aerobic waste water treatment systems either run continuously or as a fed-batch because in such fed systems chemical heterogeneities are known to occur [39] such that zones of high glucose and low oxygen exist which lead to a detrimental change in bioprocessing at larger scales due to poor mixing [22] making the design of large scale processes difficult and their performance hard to predict based on small-scale data obtained. 


\section{Acknowledgements}

Teresa Lopes da Silva and Alberto Reis wish to acknowledge Fundação Calouste Gulbenkian for financial support via post-doctoral Grants 76875 e 76876 respectively. The work was carried out with the support of FEDER funds, as a part of a study within the SAPIENS project POCTI/EQU/47689/2002 entitled "Enhancement of bubble and drop mass transfer processes using additives". 


\section{References}

[1] T.M. Lapara, J.E. Alleman, Thermophilic aerobic biological wastewater treatment, Wat. Res. 33 (1999) 895-904.

[2] G.A. Sücürü, R.S. Engelbrecht, E.S.K. Chian, Thermophilic microbial treatment strength wastewaters with simultaneous recovery of single cell protein, Biotechnol. Bioeng. 17 (1975) 1639-1662.

[3] A.F. Rosich, R.J. Colvin, Design and operational considerations for thermophilic aerobic reactors considerations for thermophilic aerobic reactors treating high strength wastes and sludges, in: Proceedings of the $52^{\text {th }}$ Industrial Waste Conference(1997), Pardue University, ed. J.E. Alleman, Ann Arbor Press, Ann Arbour, M.I., USA.

[4] D.R. Nielson, A.J. Daugulis, P.J. McLellan, A novel method of simulating oxygen mass transfer in two-phase partitioning bioreactors, Biotechnol. Bioeng. 83 (2003) 735-742.

[5] A.I. Galaction, D. Cascaval, C. Oniscu, M. Turnea, Enhancement of oxygen mass transfer in stirred bioreactors using oxygen-vectors. 1. Simulated fermentation broths, Bioprocess Biosyst. Eng. 26 (2004) 231-238.

[6] J.L. Rols, J.S. Condoret, C. Fonade, G. Goma, Mechanism of enhanced oxygen transfer in fermentation using emulsified oxygen-vectors, Biotechnol. Bioeng. 35 (1990) 427-435. 
[7] J.L. Rols, G. Goma, Enhancement of oxygen-transfer rates in fermentation using oxygen-vectors, Biotechnol. Adv. 7 (1989) 1-14.

[8] C.S. Ho, L.K. Ju, R. Baddour, Enhancing penicillin fermentations by increased oxygen solubility through the addition of n-hexadecane, Biotechnol. Bioeng. 36 (1990) 1110-1118.

[9] M. Menge, J. Mukherjee, T. Scheper, Application of oxygen vectors to Claviceps purpurea cultivation, Appl. Microbiol.Biotechnol. 55 (2001) 411-416.

[10] A.I. Galaction, D. Cascaval, M. Turnea, E. Folescu, Enhancement of oxygen mass transfer in stirred bioreactors using oxygen-vectors. 2. Propionobacterium shermanii broths, Bioprocess Biosyst. Eng. 27 (2005) 263-271.

[11] R. Giridhar, A. Srivastava, Productivity enhancement in L-sorbose fermentation using oxygen vector, Enzyme Microb. Technol. 27 (2000) 537-541.

[12] S. Jia, M. Wang, P. Kahar, Y. Park, M. Okabe, Enhanced of yeast fermentation by addition of oxygen vectors in air-lift bioreactors, J. Ferm. Bioeng. 84 (1997) 176-178.

[13] W. Jialong, Enhancement of citric acid production by Aspergillus niger using ndodecane as an oxygen vector, Process Biochem. 35 (2000) 1079-1083.

[14] L. Lai, T. Tsai, T. Wang, Application of oxygen vectors to Aspergillus terreus cultivation, J. Biosc. Bioeng. 94 (2002) 453-459. 
[15] D.Z. Wei, H. Liu, Promotion of L-asparaginase production by using n-dodecane, Biotechnol. Tech. 12 (1998) 129-131.

[16] T. Lopes da Silva, A. Mendes, R.L. Mendes, V. Calado, S. Alves, J.M.T. Vasconcelos, A. Reis, Effect of n-dodecane on Crypthecodinium cohnii fermentations and DHA production, J. Ind. Microbiol. Biotechnol. 33 (2006) 408-416.

[17] K.C. Lowe, M.R. Davey, J.B. Power, Perfluorochemicals: their applications and benefits to cell culture, Trends Biotechnol. 16, (1998) 272-277.

[18] G.T. MacLean, Oxygen diffusion rates in organic fermentation broths, Proc. Biochem. 12 (1977) 22-28.

[19] S. Zhao, S.G. Kuttava, L.K. Ju, Oxygen transfer characteristics of multiple-phase dispersions simulating water-in-oil xanthan fermentations, Bioproc. Eng. 20 (1999) 313332.

[20] P.F. Strom, Identification of thermophilic bacteria in solid-waste composting, Appl. Environ. Microbiol. 50 (1985) 906-913.

[21] T. Lopes da Silva, A. Reis, C.A. Kent, M. Kosseva, J.C. Roseiro, C.J. Hewitt, Stressinduced physiological responses to starvation periods as well as glucose and lactose pulses 
in Bacillus licheniformis CCMI 1034 continuous aerobic fermentation processes as measured by multi-parameter flow cytometry, Biochem. Eng. J. 24 (2005) 31-41.

[22] C. J. Hewitt, A. W. Nienow, The scale-up of microbial batch and fed-batch fermentation processes, Ad. Appl. Microbiol. 62 (2007) 105-135.

[23] W. Vishniac, M. Santer, The thiobacilli, Bacteriol. Rev. 21 (1957) 5-213.

[24] M. Sobotka, A. Prokop, I.J. Dunn, A. Einsele, Review of methods for the measurement of oxygen transfer in microbial systems, in Annual reports on fermentation processes, Academic Press, London, 5 (1982) pp. 127-210.

[25] C.J Hewitt, G. Nebe-Von-Caron, A.W Nienow, C.M. McFarlane. The use of multistaining flow cytometry to characterize the physiological state of Escherichia coli W3110 in high cell density fed-batch cultures, Biotevhnol. Bioeng. 63 (1999) 705-711.

[26] C. J. Hewitt, G. Nebe-von-Caron, An industrial application of multi-parameter flow cytometry: Assessment of cell physiological state and its application to the study of microbial fermentations, Cytometry 44 (2001) 179-187.

[27] G. Nebe-von-Caron, P.J. Stephens, C.J. Hewitt, J.R. Powell, R.A. Badley, Analysis of bacterial function by multi-colour fluorescence flow cytometry and single cell sorting, J. Microbiol. Meth. 42 (2000) 97-114. 
[28] H.M. Shapiro, Practical Flow Cytometry, Fourth Edition, Alan R. Liss Inc. (2003) New York.

[29] A. Reis, T. Lopes da Silva, C.A. Kent, M. Kosseva, J.C. Roseiro, C.J. Hewitt, Monitoring population dynamics of the thermophilic Bacillus licheniformis CCMI 1034 in continuous cultures using multiparameter flow cytometry, J. Biotechnol. 115 (2005) 119210.

[30] C.J. Hewitt, G. Nebe-von-Caron, The application of multi-parameter flow cytometry to monitor individual microbial cell physiological state, in: Advances Biochemical Engineering/Biotechnology, in: S.O. Enfors (Ed.), Physiological Stress Responses in Bioprocesses, Special vol. 89, Springer, 2004, pp. 197-223.

[31] P. Monfort, B. Baleux, Cell cycle characteristics and changes in membrane potential during growth of Escherichia coli as determined by cyanine fluorescent dye and flow cytometry, J. Microbiol. Meth. 25 (1996) 79-86.

[32] C. Hbid, P. Jacques, H. Razafindralambo, K. Mpoyo, M. E. Meurice, M. Paquot, P. Thonart, Influence of the production of two lipopeptides, Iturin A and Surfactin S1, on oxygen transfer during Bacillus subtilis fermentation, Appl. Biochem. Biotechnol. 8 (1996) $571-579$.

[33] P. Shariati, W.J. Mitchell, A. Boyd, F. Priest, Anaerobic metabolism in Bacillus licheniformis NCIB 6346, Microbiology 141 (1995) 1117-1124. 
[34] M. Nakano, Y. Daily, P. Zuber, D.P. Clark, Characterization of anaerobic fermentative growth of Bacillus subtilis: Identification of fermentation end products and genes required for growth, J. Bacteriol. 179 (1997) 6749-6755.

[35] T. Hoffman, M. Frankenberg, M. Marino, D. Jahan, Ammonification in Bacillus subtilis utilizing dissimilatory nitrite reductase is dependent on resDe, J. Bacteriol. 180 (1998) 186-189.

[36] J. Espinosa-de-los-Monteros, A. Martinez, F. Valle, Metabolic profiles and aprE expression in anaerobic cultures of Bacillus subtilis using nitrate as terminal electron acceptor, Appl. Microbiol. Biotechnol. 57 (2001) 379-384

[37] L.D Clements, B.S. Miller, U.N. Streips, Comparative growth analysis of the facultative anaerobes Bacillus subtilis, Bacillus licheniformis, and Escherichia coli, Syst. Appl. Microbiol. 25 (2002) 284-286.

[38] E. Rosenfeld, C. Duport, A. Zigha, P. Schmitt, Characterization of aerobic and anaerobic growth of food-borne pathogen Bacillus cereus F4430/73 strain, Can. J. Microbiol. 51 (2005) 149-158.

[39] A.J. Wolfe, The acetate switch, Microbiol. Mol. Biol. Rev. 69 (2005) 12-50. 
[40] S. O Enfors, M. Jahic, A. Rozkov, B. Xu, M. Hecker, B. Jurgen, E. Kruger, T. Schweder, G. Hamer, D. O'Beirne, N. Noisommit-Rizzi, M. Reuss, L. Boon, C. Hewitt, C. McFarlane, A. Nienow, L. Fuchs, T. Kovacs, J. Revstedt, C. Tragardh, P. C. Friberg, B. Hjertager, G. Blomsten, H. Skogman, S. Hjort, F. Hoeks, H.Y. Lin, P. Neubauer, R. van der Lans, K., Luyben, P. Vrabel, A. Manelius, Physiological responses to mixing in large bioreactors, J. Biotechnol. 85 (2001) 175-185.

[41] T. Mankad, E.B. Nauman, Modeling of microbial-growth under dual limitations, Chem. Eng. J. Biochem. Eng. J. 48 (1992) B9-B11.

[42] R. Fuchs, D.I.C. Wang, Simple system for controlling dissolved-oxygen concentration in laboratory fermentors, Biotechnol. Bioeng. 16 (1974) 1529-1536.

[43] J.D. Chung, G. Stephanopoulos, Studies of transcriptional state heterogeneity in sporulating cultures of Bacillus subtilis, Biotechnol. Bioeng. 47 (1995) 234-242. 


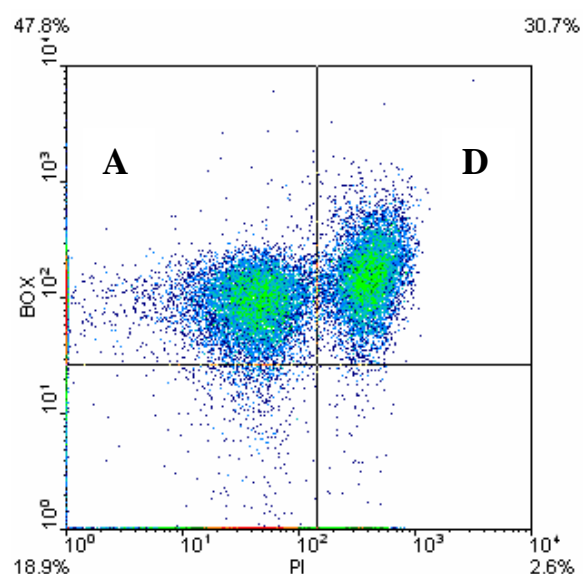

i)

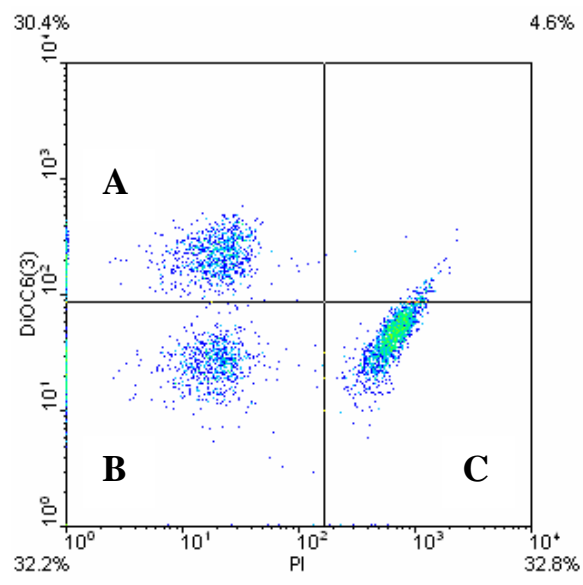

ii)

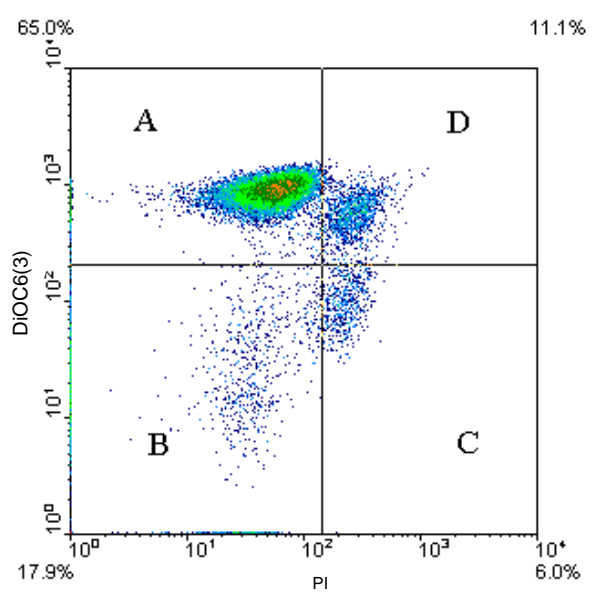

iii)

Figure 1 
Number of events

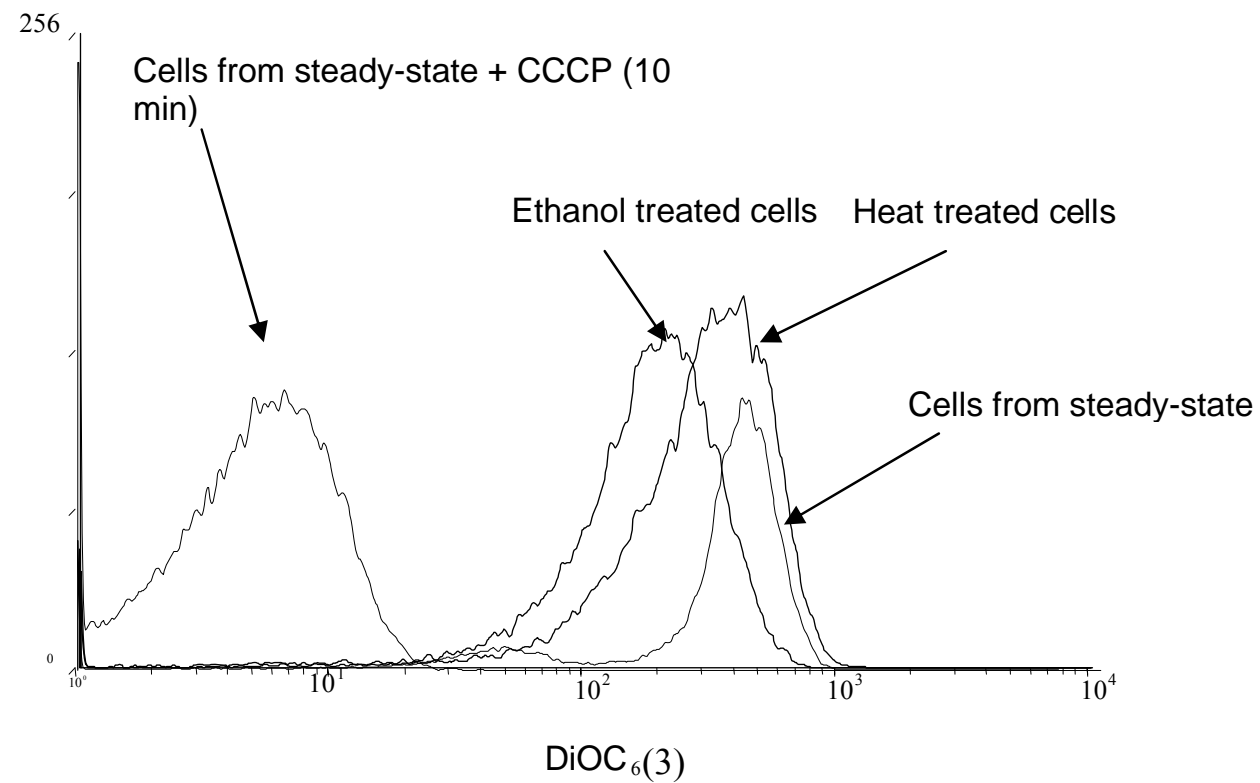

Figure 2. 


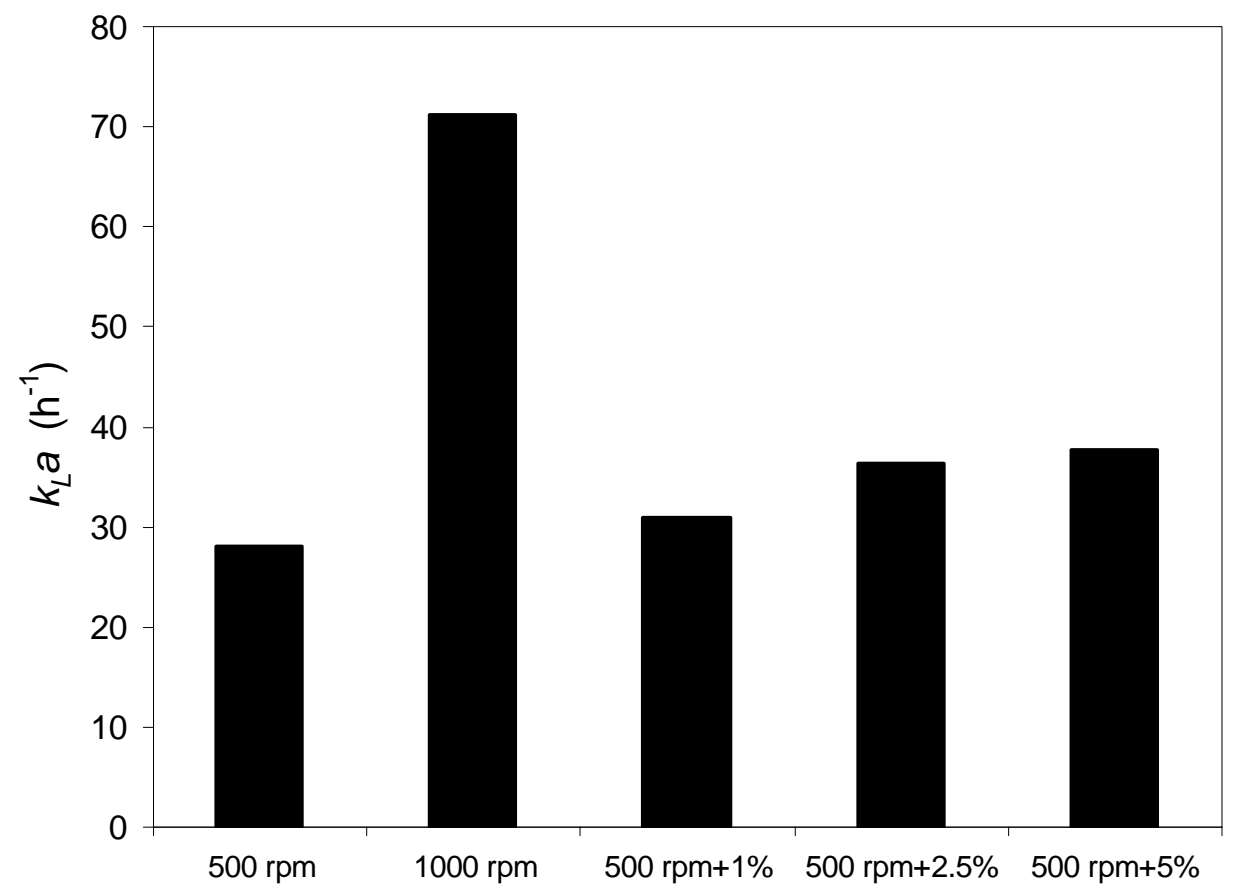

Figure 3. 
Steady-state

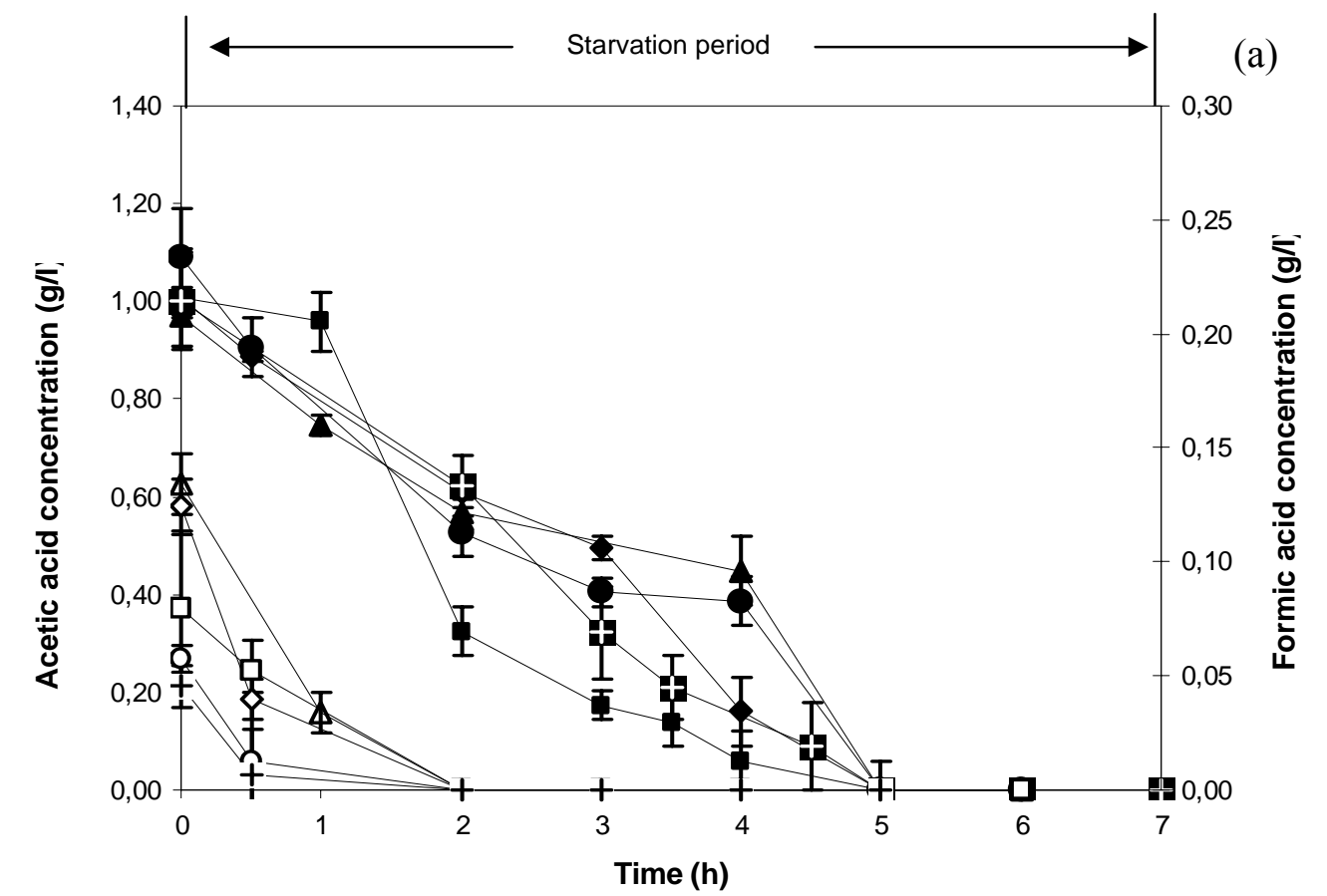

Open symbols - Formic Acid; Full symbols - Acetic acid

\begin{tabular}{|c|c|c|c|}
\hline$\longrightarrow 500 \mathrm{rpm}$ & $-1000 \mathrm{rpm}$ & $\longrightarrow 500$ rpm; $1 \%$ n-dod & $\longrightarrow 500 \mathrm{rpm} ; 2.5 \% \mathrm{n}$-dod \\
\hline$-\mathbf{t} 500 \mathrm{rpm} ; 5 \%$ n-dod & $\multimap 500 \mathrm{rpm}$ & $\triangle-1000 \mathrm{rpm}$ & - $500 \mathrm{rpm} ; 1 \% \mathrm{n}$-dod \\
\hline - $500 \mathrm{rpm} ; 2.5 \% \mathrm{n}$-dod & $+-500 \mathrm{rpm} ; 5 \%$ n-dod & & \\
\hline
\end{tabular}

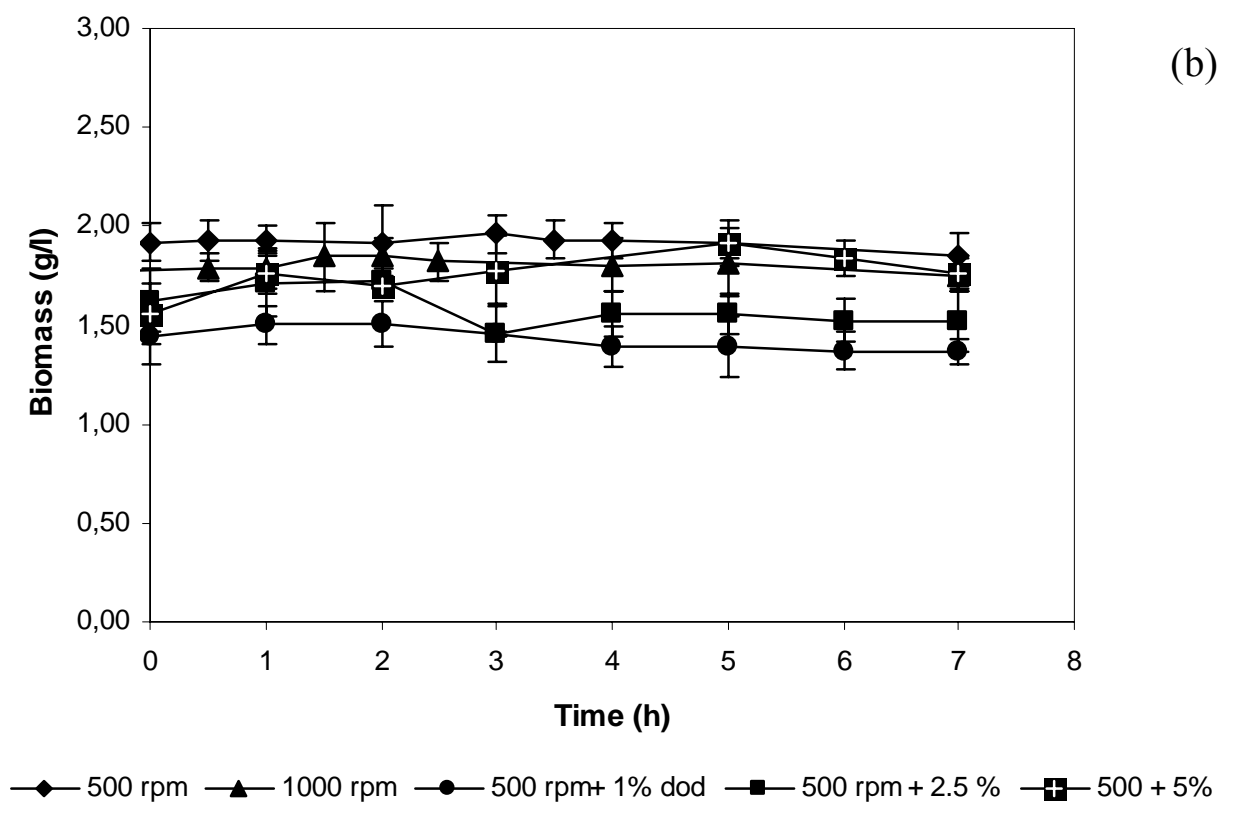

Fig. 4 


\section{Starvation period}

No n-dodecane
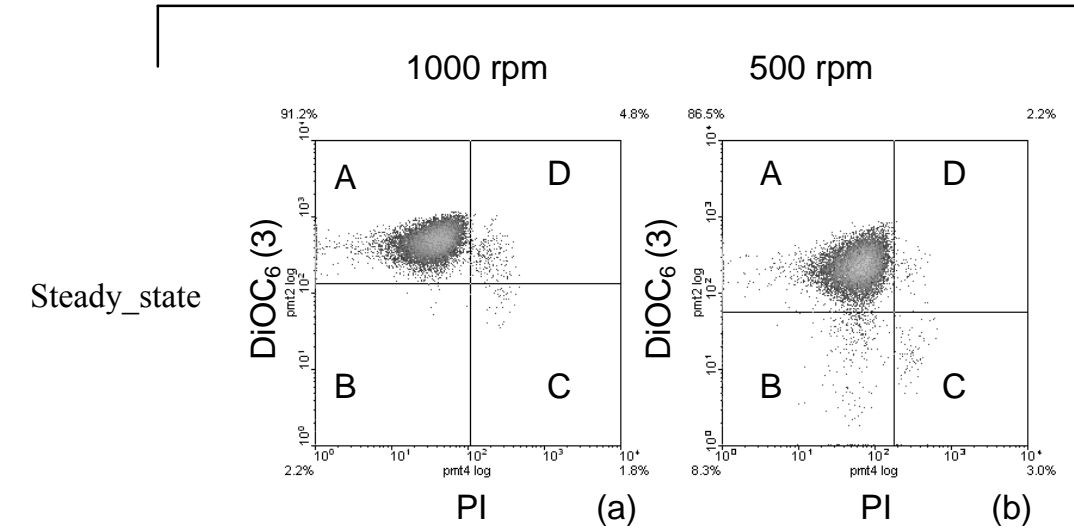

starvation period onset
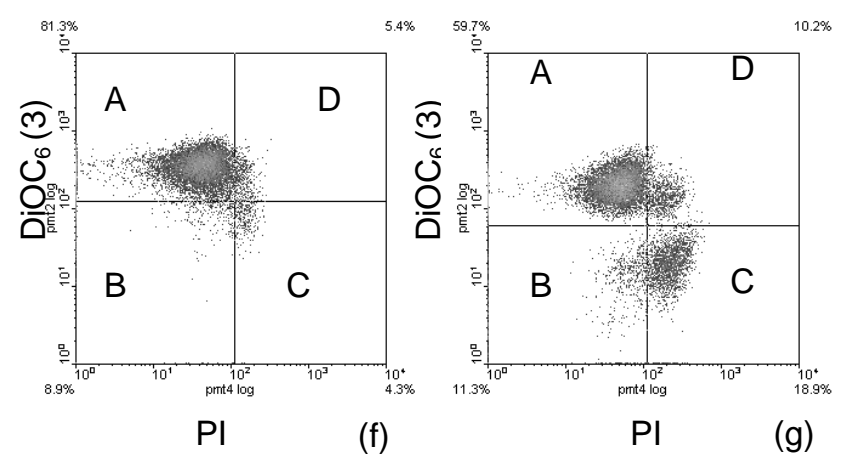

End of

the experiment

$(\mathrm{t}=6 \mathrm{~h})$
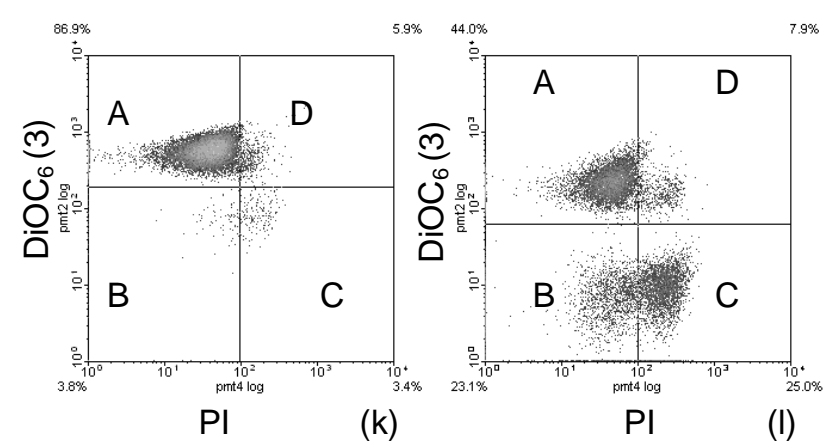

\section{With n-dodecane}
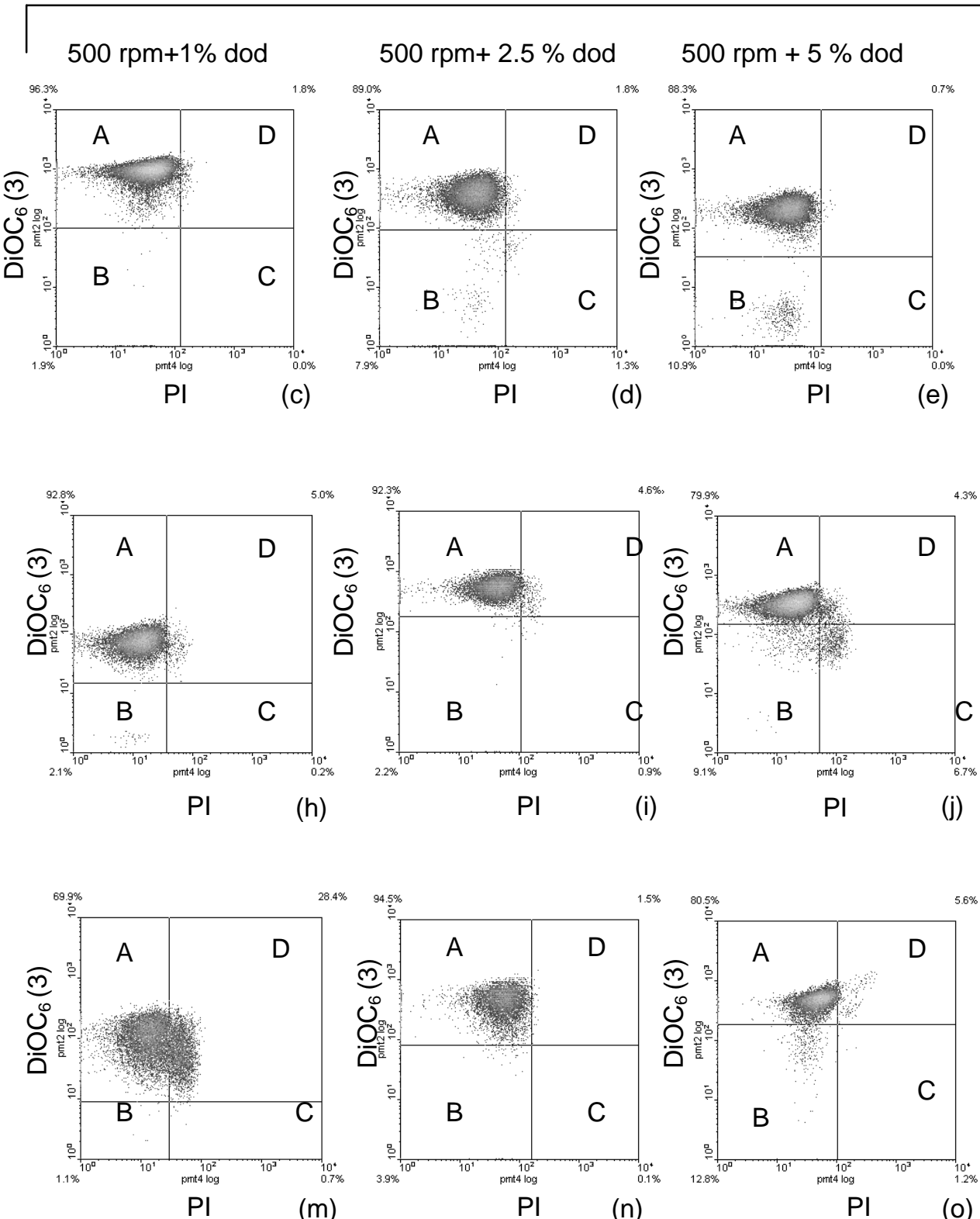

Figure 5 


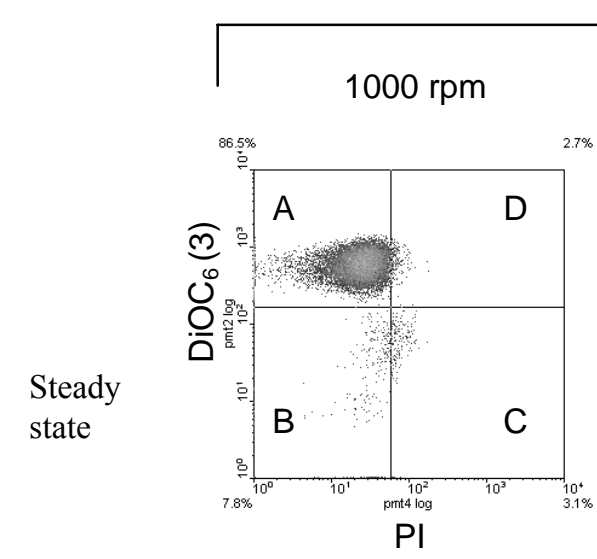

500 rpm
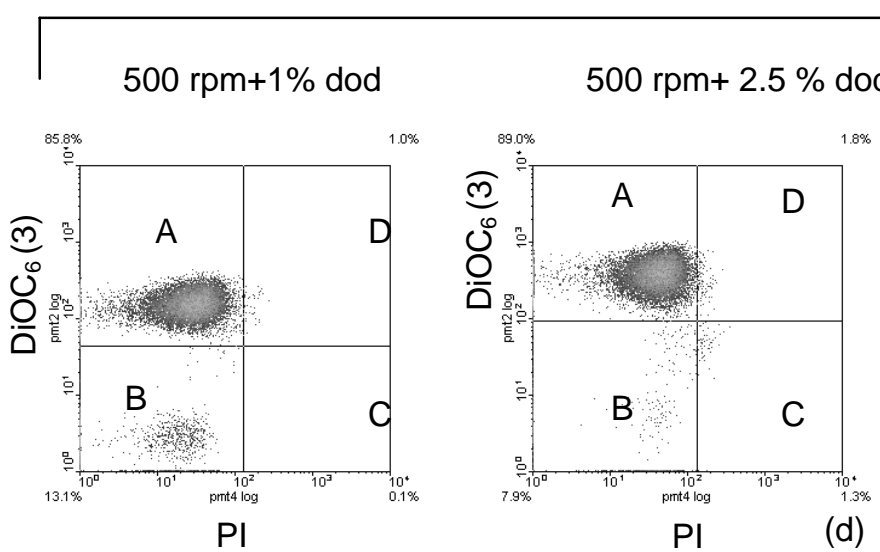

500 rpm + $5 \%$ dod
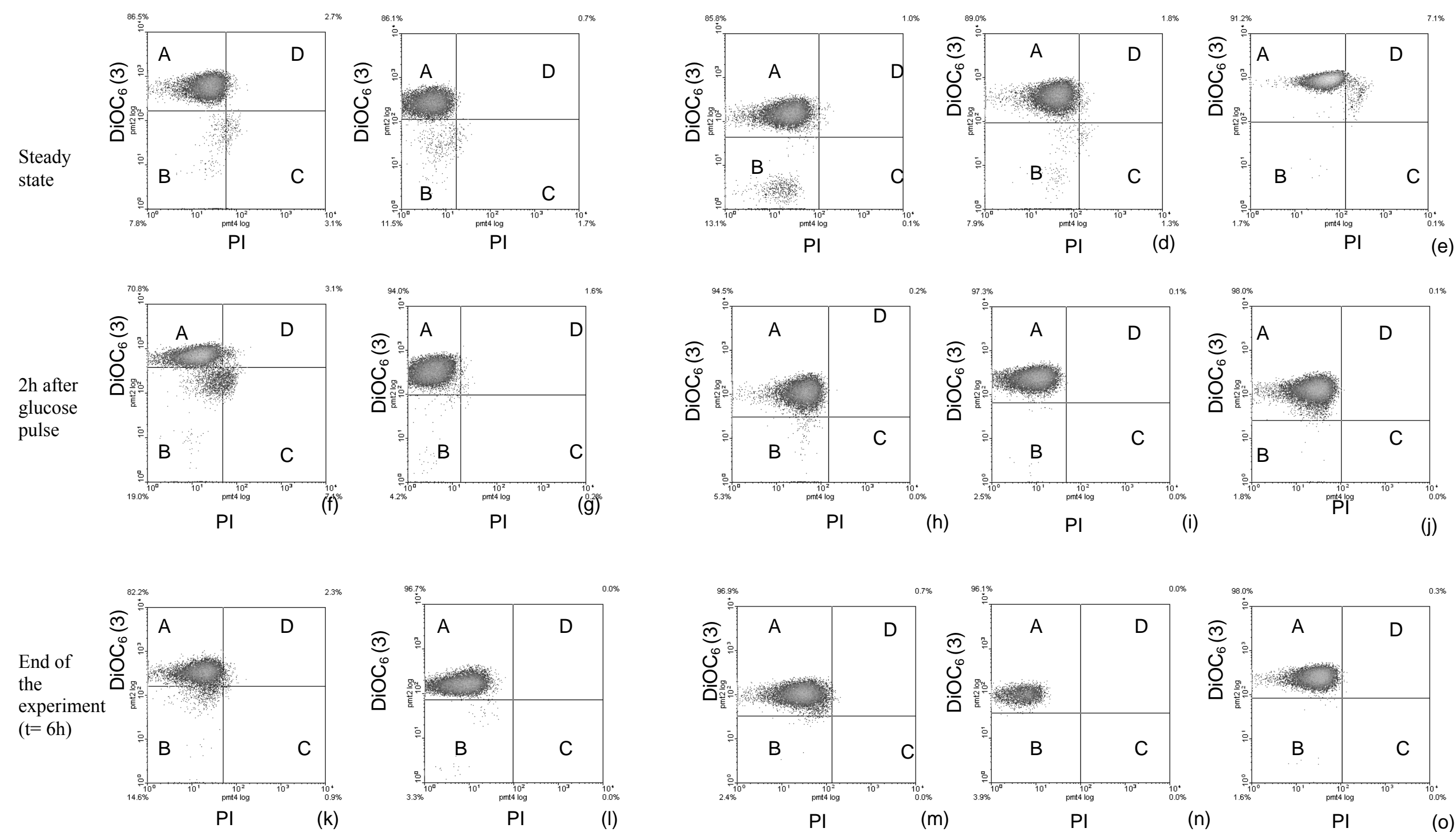

Figure 6 


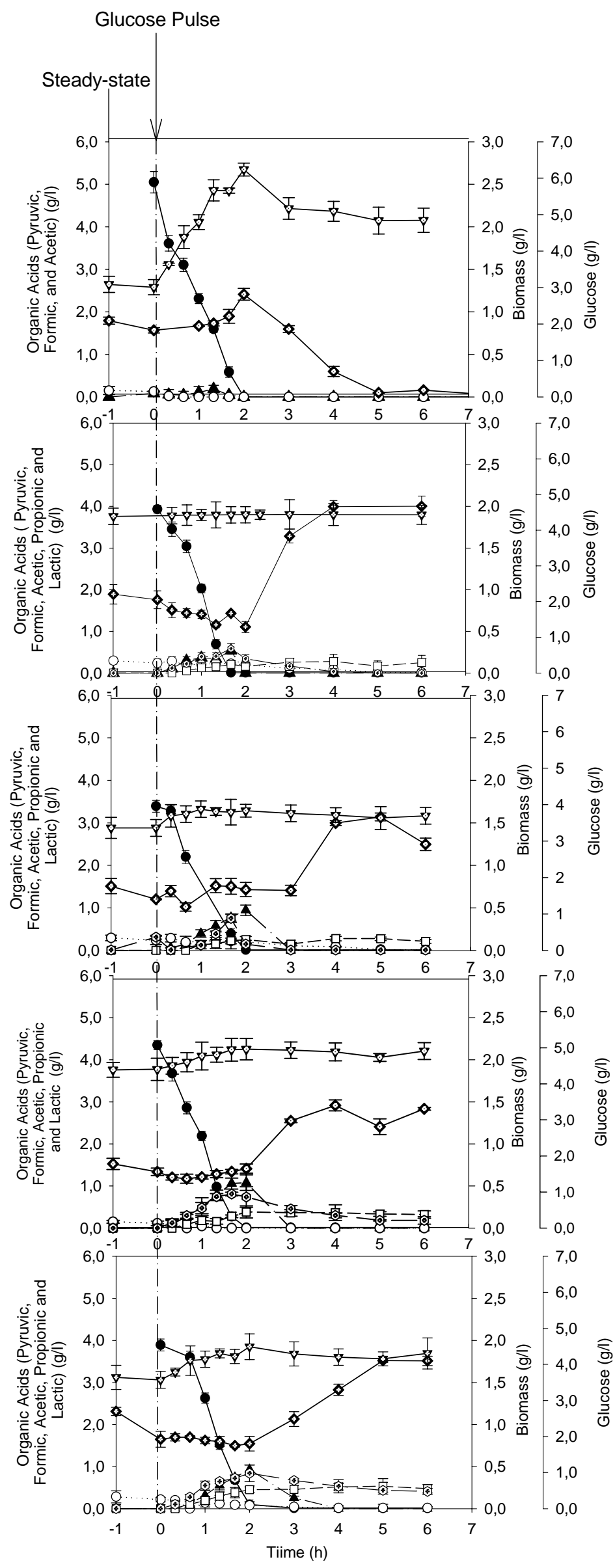

(a) $1000 \mathrm{rpm}$

(b) $500 \mathrm{rpm}$

(c) $500 \mathrm{rpm}+1 \%$ dod

(d) $500 \mathrm{rpm}+2.5 \%$ dod

(e) $500 \mathrm{rpm}+5 \%$ dod

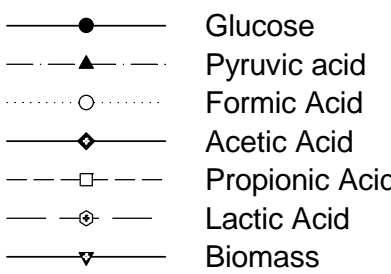

Fig. 4 
Table 1 - Organic acids volumetric uptake rates calculated for the starvation periods.

\begin{tabular}{lccccc}
\hline & $\begin{array}{c}\text { Starvation } \\
500 \mathrm{rpm}\end{array}$ & $\begin{array}{c}\text { Starvation } \\
1000 \mathrm{rpm}\end{array}$ & $\begin{array}{c}\text { Starvation } \\
500 \mathrm{rpm}+1 \% \\
n \text {-dodecane }\end{array}$ & $\begin{array}{c}\text { Starvation } \\
500 \mathrm{rpm}+2.5 \% \\
n \text {-dodecane }\end{array}$ & $\begin{array}{c}\text { Starvation } \\
500 \mathrm{rpm}+5 \% \\
n \text {-dodecane }\end{array}$ \\
\hline $\mathrm{r}_{\text {acetic }} * \mathrm{~g} \mathrm{l}^{-1} \mathrm{~h}^{-1}$ & 0.20 & 0.19 & 0.22 & 0.20 & 0.20 \\
$\mathrm{r}_{\text {formic }} * \mathrm{~g} \mathrm{l}^{-1} \mathrm{~h}^{-1}$ & 0.06 & 0.07 & 0.06 & 0.04 & 0.04 \\
\hline
\end{tabular}

*Calculated as the ratio between the organic acid steady-state concentration and the time period that the microorganism took to exhaust that organic acid.

Table 2 - Kinetic parameters calculated for the glucose pulses.

\begin{tabular}{|c|c|c|c|c|c|}
\hline & $\begin{array}{l}\text { Glucose pulse } \\
1000 \mathrm{rpm}\end{array}$ & $\begin{array}{l}\text { Glucose pulse } \\
500 \text { rpm }\end{array}$ & $\begin{array}{l}\text { Glucose pulse } \\
5000 \text { rpm }+1 \% \\
n \text {-dodecane }\end{array}$ & $\begin{array}{l}\text { Gucose pulse } \\
500 \text { rpm }+2.5 \% \\
n \text {-dodecane }\end{array}$ & $\begin{array}{l}\text { Glucose pulse } \\
500 \text { rpm+ } 5 \% \\
n \text {-dodecane }\end{array}$ \\
\hline$\mu\left(h^{-1}\right)$ & 0.20 & 0 & 0.02 & 0.07 & 0.10 \\
\hline $\begin{array}{l}Y_{X / G l u c o s e}{ }^{*} \\
\left(g \text { biomass g glucose }{ }^{-1}\right)\end{array}$ & 0.23 & 0 & 0.05 & 0.06 & 0.08 \\
\hline $\begin{array}{l}Y_{\text {acetic acid/glucose }}^{* *} \\
\left(\mathrm{~g} \text { acetic } g \text { glucose }{ }^{-1}\right)\end{array}$ & 0.15 & 0.46 & 0.41 & 0.27 & 0.26 \\
\hline $\begin{array}{l}Y_{\text {pyruvic acid/glucose }} * * \\
\text { (g pyruvic g glucose }^{-1} \text { ) }\end{array}$ & 0.03 & 0.12 & 0.24 & 0.21 & 0.20 \\
\hline $\begin{array}{l}Y_{\text {propionic acid/glucose }} * * \\
\text { (g propionic } g \text { glucose }^{-1} \text { ) }\end{array}$ & 0 & 0.06 & 0.07 & 0.07 & 0.12 \\
\hline $\begin{array}{l}Y_{\text {lactic acid/glucose }} * * \\
\left.\text { (g lactic } g \text { glucose }^{-1}\right)\end{array}$ & 0 & 0.13 & 0.19 & 0.15 & 0.18 \\
\hline
\end{tabular}

* Calculated as the ration between the biomass (concentration) produced during the glucose uptake minus the steady-state biomass concentration, and the glucose pulse concentration.

**Calculated as the ratio between the organic acid (concentration) produced during the pulse minus the steady-state organic acid concentration, and the glucose pulse concentration. 


\section{Captions to Figures}

Figure 1. i) Bacillus licheniformis cells taken from the steady state of a continuous culture and stained with a mixture of PI and BOX. Only two populations of cells could be readily identified these correspond to cells with a depolarised cytoplasmic membrane (A), stained with BOX; and cells with a depolarised permeablised cytoplasmic membrane (D), stained with both PI and BOX. ii) Late exponential Bacillus cereus cells stained with a mixture of $\operatorname{DiOC}_{6}(3)$ and PI. Three main sub-populations could be readily distinguished. These correspond to healthy cells with intact polarized cytoplasmic membranes (A) stained with $\mathrm{DiOC}_{6}(3)$; stressed cells with intact but depolarised cytoplasmic membrane cells (B) no staining; and cells with a permeablised depolarised cytoplasmic membranes (C) stained with PI only. iii) Bacillus licheniformis cells taken from the steady state of a continuous culture and stained with a mixture of $\operatorname{DiOC}_{6}(3)$ and PI. Four main sub-populations of cells could be identified. These correspond to healthy cells with intact polarized cytoplasmic membranes (A) stained with $\operatorname{DiOC}_{6}(3)$; stressed cells with intact but depolarised cytoplasmic membrane cells (B) no staining; cells with a permeablised depolarised cytoplasmic membranes (C) stained with PI only; and permeabilised cells with a disrupted cytoplasmic membrane "ghost cells" (D), stained with both $\mathrm{DiOC}_{6}(3)$ and PI.

Figure 2. B. lichenformis cells taken from the steady state of the continuous culture and either stained immediately with $\operatorname{DiOC}_{6}(3)$ and PI or incubated in the presence of $15 \mu \mathrm{gml}^{-1}$ CCCP (for $10 \mathrm{~min}$ ) or heat treated at $60^{\circ} \mathrm{C}$ (for 30s) or washed in $100 \%$ ethanol and then stained with a mixture of PI and $\mathrm{DiOC}_{6}(3)$. 
Figure 3. Variation of $k_{L} a$ with the impeller speed and with $1,2.5$ and $5 \%(\mathrm{v} / \mathrm{v}) \mathrm{n}$-dodecane added to the vessel.

Figure 4. Fermentation profiles for a steady-state continuous culture which was perturbed by a glucose starvation period (nutrient feed shut off) with and without n-dodecane added.

Figure 5. Cell samples taken at various times during a steady state continuous culture perturbed by a glucose starvation period with and without n-dodecane present stained with a mixture of PI and $\mathrm{DiOC}_{6}(3)$. When compared with the control data (Figures1 and 2) up to four main sub-populations of cells can be distinguished, corresponding to healthy cells (A), stained with $\operatorname{DiOC}_{6}(3)$; cells with a depolarised cytoplasmic membrane (B), no staining; cells with a permeabilised depolarised membrane (C), PI staining; and permeabilised depolarised cells with a disrupted cytoplasmic membrane (D), stained with both $\operatorname{DiOC}_{6}(3)$ and PI.

Figure 6. Cell samples taken at various times during a steady state continuous culture perturbed by a glucose pulse with and without n-dodecane present stained with a mixture of $\mathrm{PI}$ and $\mathrm{DiOC}_{6}(3)$. When compared with the control data (Figure1 and 2) up to four main sub-populations of cells can be distinguished, corresponding to healthy cells (A), stained with $\mathrm{DiOC}_{6}(3)$; cells with a depolarised cytoplasmic membrane (B), no staining; cells with a permeabilised depolarised membrane (C), PI staining; and permeabilised depolarised cells with a disrupted cytoplasmic membrane (D), stained with both $\mathrm{DiOC}_{6}(3)$ and $\mathrm{PI}$.

Figure 7 Fermentation profiles for a steady state continuous culture perturbed by a glucose pulse with and without n-dodecane added. 
